\title{
Metáforas gramaticais como recurso para empacotamento no texto académico
}

Grammatical metaphors as a resource for packaging in the academic text

\author{
Maria Otília Guimarães Ninin \\ Universidade Paulista \\ Norma Lírio de Leão Joseph \\ Universidade Federal de Lavras \\ Alda Maria Coimbra Maciel \\ Colégio Pedro II
}

Instituto Federal do Rio de Janeiro

\begin{abstract}
Resumo: Escrita acadêmica não é uma tarefa fácil a graduandos de qualquer curso, embora convivam com textos dessa natureza ao longo de toda a graduação. Muitos estudos têm se concentrado nas discussões sobre resenhas, abstracts e resumos, introduções de teses e dissertações, buscando suas características e modos de construir o significado do texto. No entanto, ainda são escassas as pesquisas que se debruçam sobre a seção de revisão da literatura. Nessa direção, este capítulo, a partir da análise de seções teóricas de diferentes gêneros da área de Letras/Linguística, à luz do conceito de metáfora gramatical (HALLIDAY, 1994; 2004; EGGINS; MARTIN, 1997; TAVERNIERS, 2003; SCHLEPPEGRELL, 2004; RAVELLI, 1988; SARDINHA, 2007), pretende mostrar como se realiza essa escrita e como pode ser viável, por meio de atividades de revisão do texto, propiciar aos alunos o aprendizado de uma escrita mais encapsulada, com maior densidade lexical, característica fundamental para a qualidade do texto científico.
\end{abstract}

Palavras-Chave: Linguística Sistêmico-Funcional, Metáfora Gramatical, Escrita Acadêmica. 


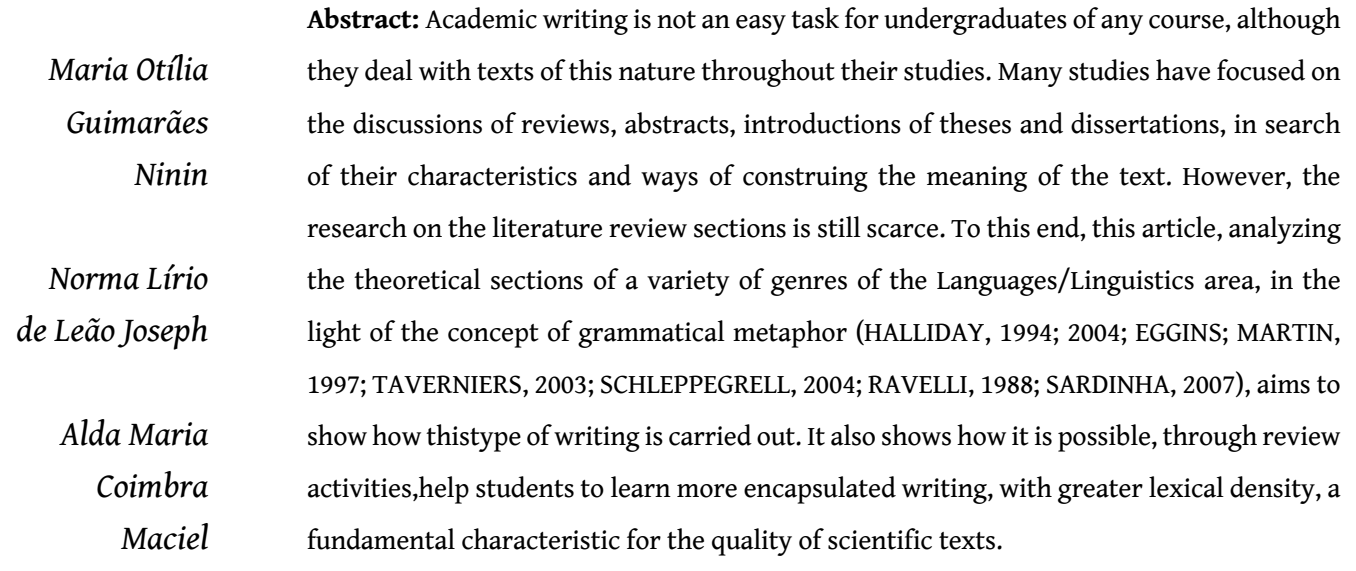

Keywords: Systemic Functional Linguistics, grammatical metaphor, academic writing.

\section{Introdução}

Um tema frequentemente gerador de debates entre os que anseiam participar efetivamente de uma comunidade acadêmica é o desafio imposto pela produção escrita de qualidade. Docentes universitários enfrentam a árdua tarefa de contribuir para o desenvolvimento do letramento acadêmico de forma que seus alunos possam produzir gêneros escritos cuja composição esteja dentro dos padrões acadêmicos em prática. Estimulando essa tarefa, estão os órgãos de fomento à pesquisa, que têm provocado, nos contextos acadêmicos, uma efervescência na produção de artigos científicos, justamente por serem estes indicadores por excelência da qualidade dos programas de pós-graduação.

Sabe-se, no entanto, que uma publicação em periódico científico percorre árdua caminhada, desde sua versão inicial à final, em decorrência das exigências cada vez mais elevadas de seus avaliadores. Para suprir esse mercado e oferecer a ele produções científicas de alto nível, muitas áreas de estudo têm se ocupado com a escrita acadêmica, destacando-se a Línguística Sistêmico-Funcional (LSF), cujo arcabouço apresenta um vasto potencial, apontando valiosos percursos de investigação. Nessa perspectiva teórica, os registros de maior prestígio na língua são os que apresentam maior densidade lexical, característica que estabelece, de certa forma, uma "medida" para o uso das palavras e orações em um texto, fortalecendo a ideia de que a escrita, na ciência, é complexa, justamente por exigir habilidades avançadas de síntese e análise a partir de múltiplas fontes, sustentadas por uma argumentação 
que exige posicionamento crítico dos autores.

O que se pretende, neste capítulo, é, portanto, discutir um dos principais conceitos relacionados a essa complexidade do texto científico, a metáfora gramatical, propondo uma reflexão sobre o ensino do encapsulamento da escrita, característica fundamental de um texto acadêmico de prestígio. Nessa direção, as seções organizam-se para: (1) discutir o conceito de metáfora gramatical e suas implicações na escrita; (2) apresentar o corpus analisado; (3) discutir excertos, retextualizando-os a partir da construção de metáforas gramaticais e, em seção final, apresentar a sistematização do que se descobriu e se propõe para o ensino.

\section{Pressupostos teóricos}

Metáforas gramaticais como recurso para empacotamento no texto acadêmico

Na LSF, teoria proposta por Michael Halliday, a linguagem, de caráter sistêmico - porque se apresenta ao falante como um sistema de escolhas - e funcional - porque essas escolhas assumem funções específicas para que o falante realize coisas -, é constituida por três metafunções: (a) a ideacional, que indica modos de codificar nossas experiências no mundo; (b) a interpessoal, que indica modos de negociar relações sociais no curso das interações; (c) a textual, que institui a organização interna do texto, segundo a hierarquia da informação (HALLIDAY, 2004). Em síntese, toda expressão linguística está fundamentada em três aspectos inseparáveis, dependentes das escolhas do falante: o que ele quer dizer (metafunção ideacional) / a quem quer dizer (metafunção interpessoal) / como quer dizer - por meio de algum texto oral ou escrito (metafunção textual).

Um falante tem ao seu dispor muitas maneiras de escolher como organizar enunciados em um texto, dependendo do contexto no qual está inserido e de suas intenções comunicativas. Na perspectiva das metafunções, os modos de realização estão, inicialmente, relacionados a dois conceitos: densidade lexical e intricacia gramatical de um texto: “Typically, written language becomes complex by being lexically dense: it packs a large number of lexical items into each clause; whereas spoken language becomes complex by being grammatically intricate: it builds up elaborate clause complexes out of parataxis and hypotaxis (HALLIDAY, 1994, p. 350). ${ }^{1}$

1. "Normalmente a linguagem escrita torna-se complexa ao ser lexicalmente densa: ela envolve um grande número de itens lexicais em cada oração; já a linguagem falada torna-se complexa por ser gramaticalmente intricada: ela constrói complexos oracionais elaborados sem parataxe e hipotaxe" (HALLIDAY, 1994, p. 350). (Tradução nossa) 
Maria Otilia

Guimarães

Ninin

Norma Lírio

de Leão Joseph

Alda Maria

Coimbra

Maciel

210

Nessa direção, quanto mais alta a densidade lexical e mais baixa a intricacia gramatical, mais próximo um texto está dos registros de maior prestígio na língua. Dentre os vários autores que discutem essa questão (GOUVEIA, 2009; SANTOS; CARMO, 2013; FARAHANI; HADIDI, 2008), estão Eggins e Martin (1997, p. 236), ao ressaltarem que a compreensão dos valores de densidade lexical e de intricacia gramatical respaldam as discussões sobre a funcionalidade dos textos, pois referem-se diretamente às características dos gêneros, indicando "modos diferentes de uso da linguagem para realizar diferentes tarefas culturalmente estabelecidas", caso nítido dos textos científicos.

A densidade lexical indica em que proporção itens lexicais (palavras de conteúdo - substantivos, verbos, adjetivos, advérbios) são utilizados em um texto; corresponde à razão entre o número de itens lexicais e o número de orações que desempenham funções oracionais, ou seja, aquelas que na escala de níveis situam-se no nível oracional, portanto, não encaixadas ${ }^{2}$. A intricacia gramatical está relacionada ao modo como as palavras e as orações são organizadas no texto; corresponde à razão entre o número de orações e o número de complexos oracionais de que essas orações fazem parte.

Halliday (2002, p. 329) explica ainda: "The lexical density increases not because the number of lexical items goes up but because the number of non-lexical items - grammatical words - goes down; and the numbers of clauses goes down even more (HALLIDAY, 2002, p. 329) ${ }^{3}$.

Escolhas realizadas pelo falante tais que tornam o texto mais denso lexicalmente e com menor intricacia gramatical são indicativas da presença do que Halliday (1994) denominou "metáfora gramatical". Mas, por que gramatical? A compreensão desse conceito passa inicialmente pela ideia de metáfora como um recurso utilizado pelo falante para designar uma coisa a partir do nome de outra (ARISTÓTELES, 353 a.C./1999). A perspectiva hallidayana de metáfora gramatical não foge a essa ideia; no entanto, sugere um outro modo de pensar a possibilidade de se designar uma coisa a partir de outra: "um recurso gramatical é usado para exprimir uma função que não lhe é intrínseca" (SARDINHA,

2. Oração encaixada corresponde, na gramática tradicional, a oração subordinada adjetiva restritiva (GOUVEIA, 2009), dentre outras.

3. “(...) a densidade lexical aumenta não porque o número de itens lexicais cresce, mas porque o número de itens não lexicais - palavras gramaticais - diminui; consequentemente, o número de orações diminui ainda mais" (HALLIDAY, 2002, p. 329). (Tradução nossa) 
2007, p. 45). Exemplificando:

\section{Exemplo (1)}

\begin{tabular}{|c|c|}
\hline $\begin{array}{l}\text { Texto } 1 \text { - menor densidade lexical } \\
\text { (DL) / maior intricacia gramatical } \\
\text { (IG) }\end{array}$ & $\begin{array}{l}\text { Texto } 2 \text { - maior densidade lexical } \\
\text { (DL) / menor intricacia gramatical } \\
\text { (IG) }\end{array}$ \\
\hline $\begin{array}{l}\text { Chomsky (1971) critica o estrutura- } \\
\text { lismo e desenvolve a linha gerativo- } \\
\text {-transformacional, que, segundo } \\
\text { o linguista, é o nível autônomo e } \\
\text { central que explica a linguagem. }\end{array}$ & $\begin{array}{l}\text { A crítica de Chomsky (1971) ao es- } \\
\text { truturalismo o conduz ao desenvol- } \\
\text { vimento da linha gerativo-transfor- } \\
\text { macional, nível autônomo e central } \\
\text { como explicação para a linguagem, } \\
\text { segundo o linguista. }\end{array}$ \\
\hline $\begin{array}{l}\text { - } \mathrm{n}^{\circ} \text { de palavras lexicais: } 14 \\
-\mathrm{n}^{\circ} \text { de orações que desempenham } \\
\text { funções oracionais: } 4\end{array}$ & $\begin{array}{l}\text { - } \mathrm{n}^{\circ} \text { de palavras lexicais: } 14 \\
-\mathrm{n}^{\circ} \text { de orações que desempenham } \\
\text { funções oracionais: } 1\end{array}$ \\
\hline $\mathrm{DL}=13 / 4=3,25$ & $\mathrm{DL}=14 / 1=14$ \\
\hline $\begin{array}{l}\text { - } \mathrm{n}^{\circ} \text { de orações: } 4 \\
\text { - } \mathrm{n}^{\circ} \text { de complexos oracionais: } 1\end{array}$ & $\begin{array}{l}\text { - } \mathrm{n}^{\circ} \text { de orações: } 1 \\
\text { - } \mathrm{n}^{\circ} \text { de complexos oracionais: } 1\end{array}$ \\
\hline$I G=4 / 1=4 \quad$ maior do que & $\mathrm{IG}=1 / 1=1$ \\
\hline
\end{tabular}

Metáforas

gramaticais

como

recurso para

empacota-

mento no texto

acadêmico

Quadro 1: Metáfora gramatical como organizadora do texto de alta densidade lexical

No exemplo acima, pode-se observar que os verbos do Texto 1 (critica, desenvolve, explica) transformam-se em nomes no Texto 2 (crítica, desenvolvimento, explicação). Vê-se também que o Texto 1 apresenta intricacia gramatical maior do que a do Texto 2. Esses textos caracterizam, respectivamente, o que Halliday (1994) denomina modo congruente e modo não congruente de realização dos significados na língua. Modo congruente é aquele que parece ser o mais típico de dizer, o de uso mais frequente e estável, em que cada elemento exerce sua função primária: verbos assumem o papel de processos, substantivos remetem aos participantes, advérbios às circunstâncias, deixando transparecer uma "harmonia entre os estratos do texto" (SARDINHA, 2007, p. 47). Já o modo não congruente destaca a tensão entre os elementos do texto, justamente por conta das mudanças em suas funções primárias. Instaura-se aí a metáfora gramatical.

\footnotetext{
The metaphorical mode has come to be associated with prestige discourses of power and authority. But what is the underlying significance of this kind of 're-mapping' between the semantics
}

4. Forma congruente selecionada do corpus analisado - Artigo Científico (AC) 


\section{Maria Otilia}

Guimarães

Ninin

Norma Lírio

de Leão Joseph

Alda Maria

Coimbra

Maciel and the grammar? (...) the ideational metafunction is a resource for construing our experience of the world that lies around us and inside us. In the congruent mode, the grammar construes sequences (of figures), figures and elements as the basic phenomena of experience, (...) In the metaphorical mode, the model is enriched through combinations of these categories: in addition to the congruent categories - sequences construed as figures, figures construed as elements, and so on (HALLIDAY, 2004, p. 640). ${ }^{5}$

Voltando ao Quadro 1, no Texto 1, tem-se, por exemplo, em "Chomsky critica o estruturalismo e desenvolve a linha gerativo-transformacional", participantes e processos ("Chomsky" no papel de Dizente e "o estruturalismo" no papel de Verbiagem para o processo verbal "critica"; "linha gerativo-transformacional" no papel de Fenômeno para o processo mental "desenvolve"). No Texto 2, realizado metaforicamente, em "A crítica de Chomsky ao estruturalismo o conduz ao desenvolvimento da linha gerativo-transformacional" tem-se uma mudança que torna mais complexa a relação entre os níveis da léxico-gramatica e da semântica do discurso: o que antes era processo é agora realizado por um nome ("critica" realiza-se como "crítica"); o que era Verbiagem ("o estruturalismo") assume a função de modificador ("ao estruturalismo"); o que era processo passa a ser um nome ("desenvolve" realiza-se como "desenvolvimento") e assim por diante.

Em relação aos modos congruente e não congruente, Halliday (1994) destaca:

Nor is it to suggest that a set of variants of this kind will be totally synonymous; the selection of metaphor is itself a meaningful choice, and the particular metaphor selected adds further semantic features. But they will be systematically related in meaning, and therefore synonymous in certain respects" (HALLIDAY, 1994, p. 342)6.

5. "O modo metafórico tem sido associado aos discursos de prestígio, poder e autoridade. Mas qual é o significado subjacente a este tipo de "remapeamento" entre a semântica e a gramática? (...) A metafunção ideacional é um recurso para interpretar nossa experiência do mundo, que está ao nosso redor e dentro de nós. No modo congruente, a gramática constrói sequências (de figuras), figuras e elementos como os fenômenos básicos de experiência (...). No modo metafórico, o modelo é enriquecido por meio de combinações dessas categorias: além das categorias congruentes - sequências construídas como figuras, figuras entendidas como elementos, e assim por diante." (HALLIDAY, 2004, p. 640) (Tradução nossa)

6. “Não se está sugerindo que um conjunto de variantes desse tipo [congruente e não congruente] será totalmente sinônimo; a seleção da metáfora é em si mesma uma escolha significativa, e a metáfora especial selecionada adiciona mais recursos semânticos. Eles estão relacionados sistematicamente em significado, e, portanto, sinônimos, em certos aspecto." (HALLIDAY, 1994, p. 342). (Tradução nossa) 
As metáforas gramaticas realizam-se em duas perspectivas: ideacional (ou de transitividade) e interpessoal: a primeira, indicando modos alternativos para a expressão de significados experienciais; a segunda, indicando modos alternativos para a expressão de significados modais ou de comandos. Na escrita acadêmica, a metáfora ideacional é responsável pelo encapsulamento ou empacotamento do texto, o que o torna mais denso lexicalmente, como já dito anteriormente. Por esse motivo, a atenção, neste capítulo, volta-se para a metáfora gramatical ideacional e seus modos de realização: (a) o uso metafórico processual; (b) o uso de nominalizações para representar processos.

\section{Metáforas gramaticais como recurso para empacota- mento no texto acadêmico}

O exemplo (2) mostra o uso metafórico processual e o uso de nominalizações para representar processos.

Dentre os modos de realização da metáfora gramatical ideacional está a nominalização, recurso frequentemente utilizado para realizações léxico-gramaticais de categorias semânticas mais metafóricas do que típicas ou congruentes (HEYVAERT, 2003, p. 65). Consiste, basicamente, em utilizar uma forma nominal para expressar o significado de um processo ou de um qualificador. Uma vez que a metáfora gramatical implica, dentre outros processos, a transformação de ideias mais concretas em mais abstratas, com a substituição de processos verbais por nominalizações (HALLIDAY, 1994; HEYVAERT, 2003), esta última constitui um recurso basilar para a composição de textos produzidos em contextos acadêmicos e científicos.

7. "Metáfora ideacional do tipo ideacional é principalmente uma estratégia que nos permite transformar nossa experiência de mundo: o modelo de experiência interpretado de modo congruente é reconstruído no modelo metafórico, criando um modelo distante de nossa experiência cotidiana, - mas o que fez a ciência moderna possível" (HALLIDAY, 2004, p. 646). (Tradução nossa) 


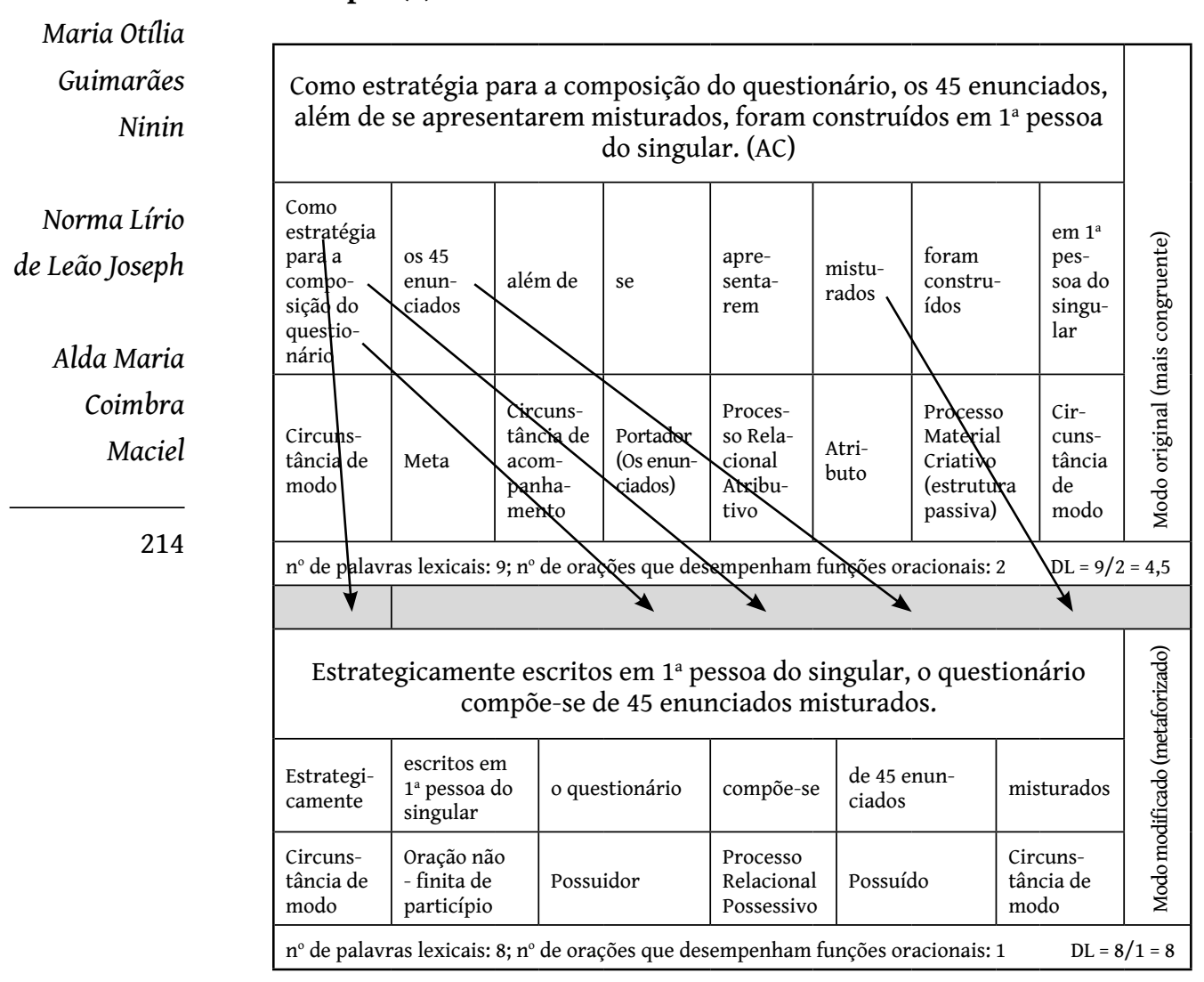

Quadro 2: Metáfora Gramatical Ideacional

Sobre a nominalização, afirma Halliday:

is the single most powerful resource for creating grammatical metaphor (...) processes (congruently worded as verbs) and properties (congruently worded as adjectives) are reworded metaphorically as nouns; instead of functioning in the clause, as Process or Attribute, they function as Thing in the nominal group (HALLIDAY, 1994, p. 352; HALLIDAY, 2004, p. 656) 9 .

8. Forma mais congruente selecionada do corpus analisado - Artigo Científico (AC).

9. “(...) é um poderoso recurso para a criação de metáfora gramatical (...) processos (congruentemente formulados como verbos) e propriedades (congruentemente formulados como adjetivos) são reformulados metaforicamente como substantivos; em vez de funcionar na frase como processo ou atributo, funcionam como coisa no grupo nominal." (HALLIDAY, 1994, p. 352; 2004, p. 656) (Tradução nossa) 
Do ponto de vista linguístico, a nominalização refere-se à mudança no uso de um verbo ou um adjetivo para um substantivo, com ou sem transformação morfológica, de modo que a palavra passa a ser o núcleo de um sintagma nominal. Quando um verbo é nominalizado, torna-se conceito e deixa de ser uma ação (TAVERNIERS, 2003). Exemplificando:

(3) Como estratégia para a composição do questionário (...) (AC) - modo metaforizado

Como estratégia para compor o questionário, (...) - modo congruente

(4) Acreditamos que (...), o que nos leva à formulação das seguintes hipóteses: (...) (AC) - modo metaforizado

Metáforas gramaticais como recurso para empacotamento no texto acadêmico

Acreditamos que (...), o que nos leva a formular as seguintes hipóteses: (...) - modo congruente

Em relação ao uso, na ciência, de metáforas procedentes de nominalizações, Halliday ressalta que

(...) probably evolved first in scientific and technical registers, where it played a dual role: it made it possible on the one hand to construct hierarchies of technical terms, and on the other hand to develop an argument step by step, using complex passages 'packaged' in nominal form as Themes. It has gradually worked its way through into most other varieties of adult discourse, in much of which, however, it loses its original raison d'être and tends to become merely a mark of prestige and power" (HALLIDAY, 1994, p. 353; HALLIDAY, 2004, p. 657) ${ }^{10}$.

Também Webster (2009, p. 4), instigando seus interlocutores sobre o uso das nominalizações na ciência, retoma um argumento de Halliday:

10. "[a nominalização] provavelmente evoluiu pela primeira vez em registros científicos e técnicos, onde desempenhou um papel duplo: tornou possível, por um lado, a construção de hierarquias de termos técnicos, e por outro, desenvolveu um argumento passo a passo, usando passagens complexas 'encapsuladas' em forma nominal como temas. Ela foi gradualmente trabalhada juntamente com outras variedades do discurso adulto, perdendo, dessa forma, sua razão original de existir e tendendo tornar-se apenas uma marca de prestígio e poder." (HALLIDAY, 1994, p. 353; HALLIDAY, 2004, p. 657). (Tradução nossa) 
Maria Otilia

Guimarães

Ninin

Norma Lírio

de Leão Joseph

Alda Maria

Coimbra

Maciel

216

The core of a scientific text was the development of a chain of reasoning (ultimately based on experiments) in which each step led on to the next. But in order to lead on to the next step you have to be able to repeat what has gone before and is now being used as a springboard for the next move" (HALLIDAY, apud WEBSTER, 2009: 4). ${ }^{11}$

Afirma, ainda, o autor: "The grammar 'packages' what has gone before, the preceding step in the experiment, by nominalizing the process (attribute or event), and making the Medium of that Process a "possessive' modifier" (WEBSTER, 2009, p. 4). ${ }^{12}$

Nominalizações mudam a distribuição das informações, reduzindo o número de orações usado para dar essas informações, contribuindo para o desaparecimento de opiniões explícitas e subjetivas. Fairclough (2003, p. 42-3), também discutindo nominalizações, destaca o fato de que seu uso envolve, em determinadas situações, a "perda de certos elementos semânticos das orações (...) e a exclusão de participantes nas orações" ${ }^{13}$. Nos textos acadêmicos, isso pode ser observado quando o autor apresenta generalizações ou em situações em que deseja apagar a responsabilidade de um agente participante. A nominalização, portanto, ao suprimir parte da realidade, é um dos recursos mais utilizados em textos persuasivos. Exemplificando:

(5) A afirmação de que as escolhas realizadas na produção do discurso podem ser inconscientes não toma como base... (TCC)

Nesse exemplo, ao optar pela nominalização "afirmação", o autor não só está substituindo um processo - afirmar -, mas eliminando o participante humano, aquele que fez a afirmação, eximindo-o da responsabilidade sobre o que é enunciado.

\footnotetext{
11. "O núcleo de um texto científico é o desenvolvimento de uma cadeia de raciocínio (fundamentalmente baseada nas experiências), em que cada etapa leva à próxima. Mas, a fim de prosseguir, você tem que ser capaz de repetir o que se passou antes e agora está sendo usado como um trampolim para o próximo passo.” (HALLIDAYY, apud WEBSTER, 2009, p. 4) (Tradução nossa)

12. "A gramática 'empacota' o que se passou antes - a etapa anterior da experiência - nominalizando o processo (atributo ou evento) e fazendo do meio desse processo um modificador 'possessivo". (WEBSTER, 2009, p.4) (Tradução nossa)

13. Texto original: "Nominalizations characteristically involves the 'loss' of certain semantic elements of clauses (...) it may also involves the exclusion of Participants in clauses” (FAIRCLOUGH, 2003, p.42-3).
} 
Estabelecendo diferentes tipos de metáfora gramatical e examinando como podem ser reconhecidas por meio da transitividade, Ravelli (1988), baseada em Halliday ${ }^{14}$ (1985), propõe um método de análise que oferece mais detalhes do modo como a metáfora gramatical é usada em textos reais. Após investigar textos sobre o campo do desarmamento nuclear em busca de metáforas gramaticais, Ravelli chegou à seguinte classificação:

\begin{tabular}{|c|c|c|c|}
\hline $\begin{array}{l}\text { Função no modo } \\
\text { congruente (c) }\end{array}$ & $\stackrel{M}{\rightarrow}$ & $\begin{array}{l}\text { Função no modo } \\
\text { metaforizado (m) }\end{array}$ & $\begin{array}{l}\text { Exemplos (indicados por (c) os con- } \\
\text { gruentes e por (m) os metaforizados) }\end{array}$ \\
\hline $\begin{array}{l}\text { 1a. Processo } \\
\text { material }\end{array}$ & $\stackrel{M}{\Delta}$ & $\begin{array}{l}\text { Coisa/grupo } \\
\text { nominal }\end{array}$ & $\begin{array}{l}\text { (c) ... MESCLANDO outros dois.... }{ }^{\Perp}(\mathrm{m}) \text {... por } \\
\text { ser uma MESCLA dos outros dois... (TCC) } \\
\text { (c) ... ao UTILIZAR os recursos linguísticos }{ }^{\natural}(\mathrm{m}) \\
\text {... a UTILIZAÇÃO dos recursos linguísticos... (DO) }\end{array}$ \\
\hline $\begin{array}{l}\text { 1b. Processo } \\
\text { mental }\end{array}$ & $\stackrel{\leftrightarrow}{\Rightarrow}$ & $\begin{array}{l}\text { Coisa/grupo } \\
\text { nominal }\end{array}$ & 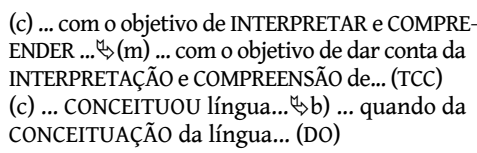 \\
\hline $\begin{array}{l}\text { 1c. Processo } \\
\text { relacional }\end{array}$ & $\stackrel{M}{\Rightarrow}$ & $\begin{array}{l}\text { Coisa/grupo } \\
\text { nominal }\end{array}$ & 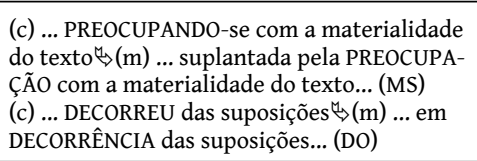 \\
\hline $\begin{array}{l}\text { 1d. Processo } \\
\text { verbal }\end{array}$ & $\stackrel{M}{\Rightarrow}$ & $\begin{array}{l}\text { Coisa/grupo } \\
\text { nominal }\end{array}$ & $\begin{array}{l}\text { (c) ... tanto um quanto outro MENCIONAM a } \\
\text { questão.... }\rangle_{(\mathrm{m})} \text {... tanto os PCN quanto o PNLD } \\
\text { fazem MENÇÃO a essa... (TCC) } \\
\text { (c) ... EXPLICANDO as regularidades... }{ }_{\text {(m) }}(\mathrm{m}) \text { bus- } \\
\text { cando EXPLICAÇÃO para as regularidades... (DO) }\end{array}$ \\
\hline $\begin{array}{l}\text { 1e. Processo } \\
\text { comportamental }\end{array}$ & $\Leftrightarrow$ & $\begin{array}{l}\text { Coisa/grupo } \\
\text { nominal }\end{array}$ & 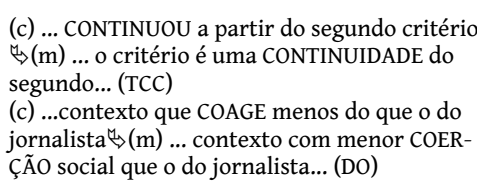 \\
\hline 2. Processo & $\Leftrightarrow$ & $\begin{array}{l}\text { Epíteto, classifi- } \\
\text { cador/ adjetivo }\end{array}$ & 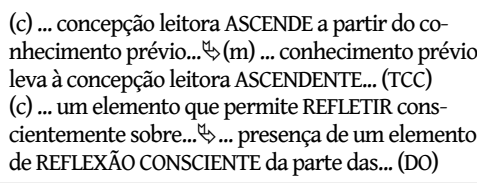 \\
\hline $\begin{array}{l}\text { 3a. Qualidade } \\
\text { de uma coisa }\end{array}$ & $\stackrel{M}{\Rightarrow}$ & $\begin{array}{l}\text { Coisa/grupo } \\
\text { nominal }\end{array}$ & $\begin{array}{l}\text { (c) ... autor desenvolve ainda questões sobre } \\
\text { ANGÚSTIA... (MS) }{ }^{\Perp} \ldots \text { questões ANGUSTIAN- } \\
\text { TES são desenvolvidas... } \\
\text { (c) ... quanto à autoria das normas de TRABA- } \\
\text { LHO, nenhum... (AC) } \uplus_{\supset} \ldots \text { quanto à autoria de } \\
\text { normas TRABALHISTAS, nenhum ... }\end{array}$ \\
\hline $\begin{array}{l}\text { 3b. Qualidade } \\
\text { de processo }\end{array}$ & $\stackrel{M}{\Rightarrow}$ & $\begin{array}{l}\text { Coisa/grupo } \\
\text { nominal }\end{array}$ & $\begin{array}{l}\text { (c) sente-se PERTENCENTE a.... }{ }_{\text {... sentido de }} \\
\text { PERTINÊNCIA entre o material e... (MS) }\end{array}$ \\
\hline $\begin{array}{l}\text { 3c. Qualidade } \\
\text { de um processo }\end{array}$ & $\stackrel{M}{\Rightarrow}$ & $\begin{array}{l}\text { Epíteto, classifi- } \\
\text { cador/ adjetivo }\end{array}$ & $\begin{array}{l}\text { (c) ... conclui PARCIALMENTE que.... } \rightarrow(\mathrm{m}) \text {... } \\
\text { uma conclusão PARCIAL é que... (MS) } \\
\text { (c) ... refletiu CRITICAMENTE sobre... }(\mathrm{m}) \text {... de- } \\
\text { senvolver reflexão CRÍTICA sobre os textos... (TCC) }\end{array}$ \\
\hline
\end{tabular}

Metáforas gramaticais como recurso para empacotamento no texto acadêmico

14. O elemento chamado por Halliday de "coisa" é o núcleo semântico do grupo nominal. Pode ser substantivo comum, nome próprio ou pronome pessoal” (HALLIDAY, 1994, p.189) 


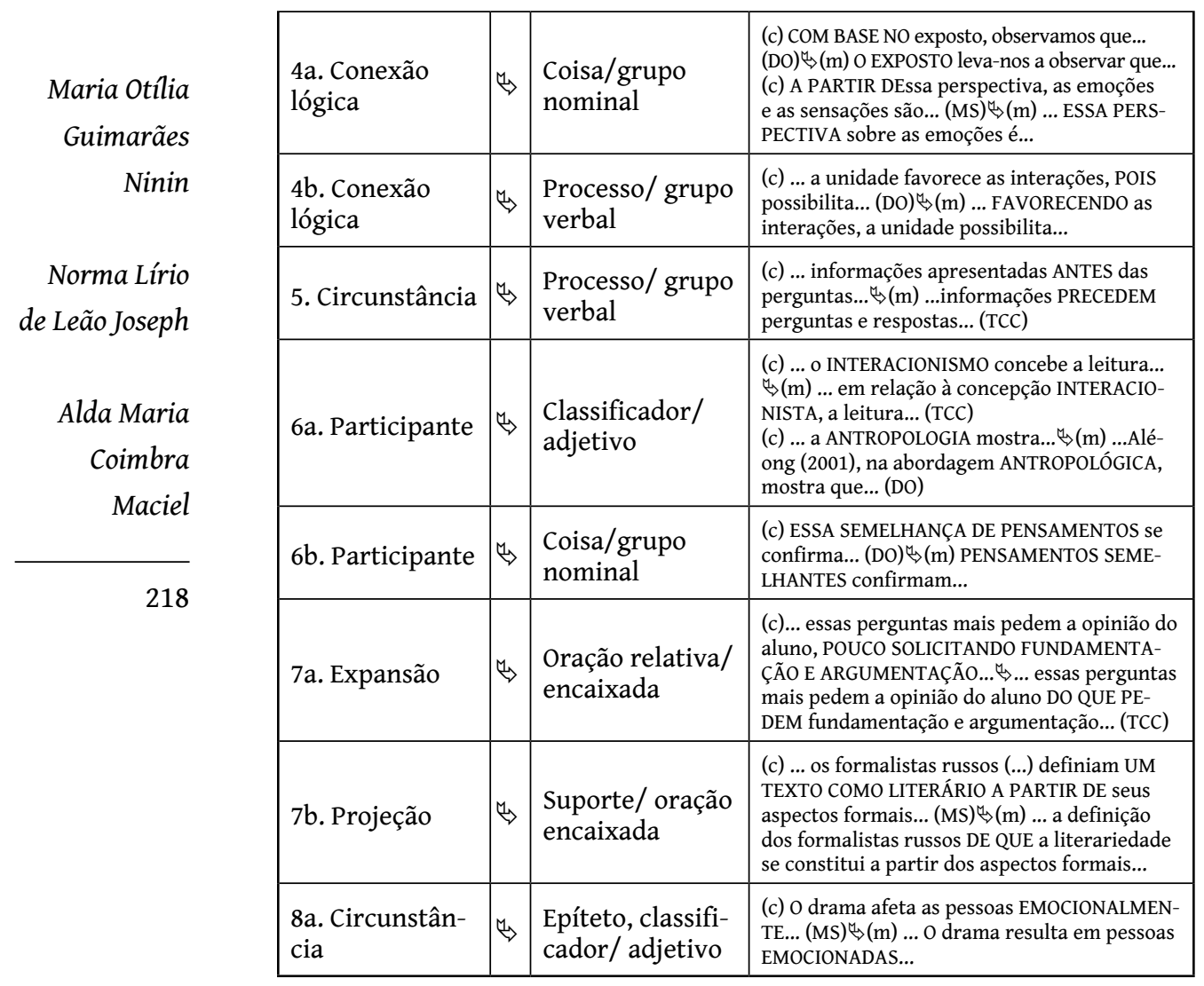

Quadro $3^{15}$ : Reconhecimento da metáfora gramatical por meio da transitividade

Fonte: Baseado em Halliday (1985). Adaptado de Ravelli (1988).

\section{Pressupostos metodológicos}

O corpus utilizado na investigação é composto por quatro textos de gêneros acadêmicos distintos da área de Letras/Linguística, selecionados de sites de universidades brasileiras: um trabalho de conclusão de curso (TCC), uma dissertação (MS), uma tese (DO) e um artigo científico (AC) publicado em revista Qualis A. Para identificação, em cada texto do corpus, de ocorrências da metáfora gramatical e análise dos mecanismos de realização do encapsulamento do texto foram utilizadas as ferramentas do programa computacional WordSmith Tools (SCOTT, 2009), Wordlist e Concord, no seguinte percurso metodológico: (a) levantamento das nominalizações - busca, na Wordlist, 15. As categorias apresentadas no Quadro 3 seguem a denominação original de Ravelli (1988). Os exemplos apresentados foram selecionados do corpus analisado: AC - artigo científico; TCC - trabalho de conclusão de curso - graduação; MS - dissertação; DO - tese, ou elaborados pelas autoras deste capítulo. 
de palavras com os sufixos ção/ções (ex. elaboração), mento/mentos (ex. conhecimento), cia/cias (ex. referência), ssão/ssões (ex. transmissão), dor/dores (ex. trabalhador), e suas linhas de concordância; (b) levantamento dos processos e linhas de concordância; (c) análise das linhas de concordância envolvendo nominalizações e processos. A busca por nominalizações permitiu identificar a presença de metáforas gramaticas ideacionais e seu uso nos textos analisados; já a análise dos processos favoreceu a identificação de complexos oracionais encapsulados e congruentes.

A investigação não teve como objetivo realizar um levantamento quantitativo das ocorrências de metáforas gramaticais nos textos selecionados. Não se focalizou, portanto, a frequência de sua utilização, mas sua composição e implicações nos gêneros acadêmicos escritos para,

Metáforas gramaticais como recurso para empacotamento no texto acadêmico posteriormente, orientar propostas de ensino. Nessa perspectiva, a seção a seguir apresenta excertos selecionados do corpus, em duas direções: (1) a escrita real do autor identificada por (AC) - artigo científico, (DO) - tese; (MS) - dissertação; (TCC) - trabalho de conclusão de curso - graduação; (2) a forma metaforizada ou a forma congruente relativa ao texto original.

\section{Análise e discussão}

Como já dito, o objetivo deste capítulo é discutir o modo como conceitos teóricos são apresentados em diferentes gêneros acadêmicos escritos, mostrando como se realiza essa escrita e como pode ser viável, por meio de atividades de revisão do texto, propiciar aos alunos o aprendizado de uma escrita mais encapsulada, com maior densidade lexical. Nessa perspectiva, a seção está organizada por meio de quadros que mostram sequências textuais metaforizadas gramaticalmente, ditas não congruentes, e suas correspondentes no modo mais congruente de escrita. Vale ressaltar que trechos dos textos analisados - TCC, dissertação, tese e artigo científico - não são categoricamente congruentes ou não congruentes, mas apresentam níveis de congruência: mais congruentes quando pouco recorrem aos mecanismos de metaforização; não congruentes quando a recorrência a esses mecanismos é mais alta. 


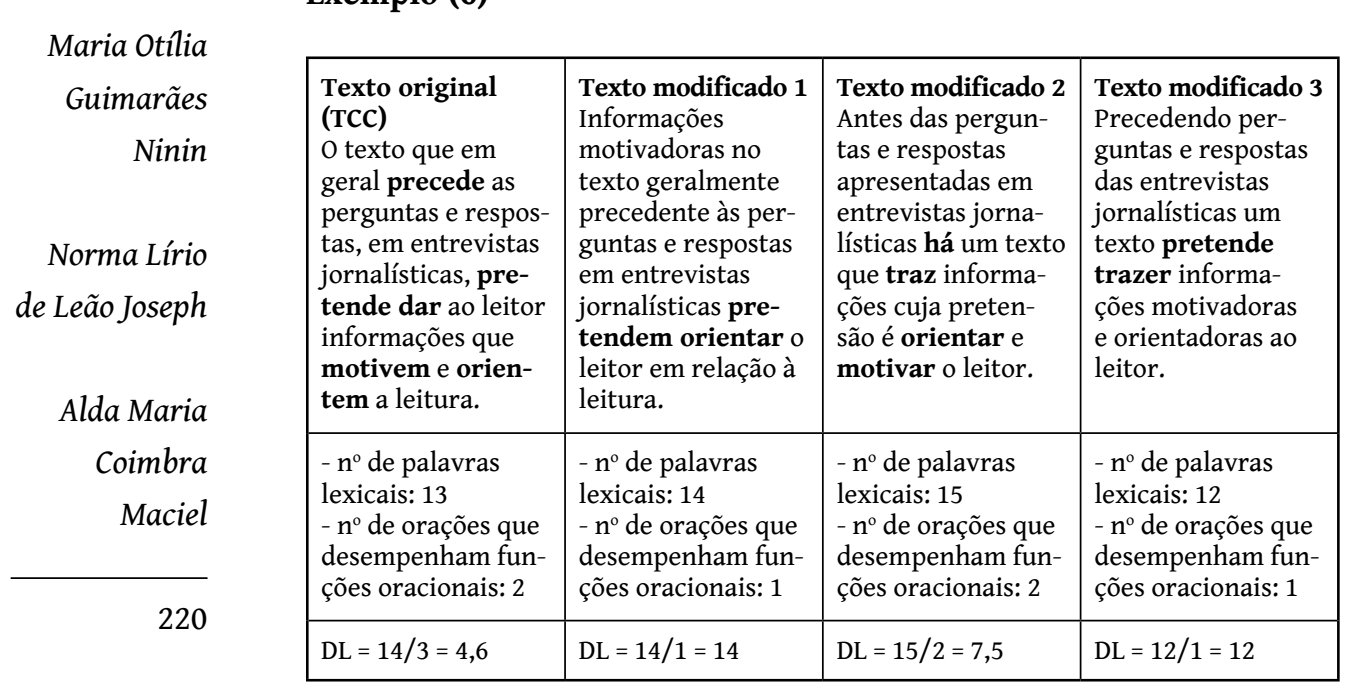

No exemplo (6), pode-se iniciar a discussão destacando a oração dominante: "O texto pretende", associada a outras orações em função das pretensões comunicativas do autor. Percebe-se, tanto nesse texto original quanto nos modificados, trechos metaforizados $O$ que se pretende destacar, no entanto, é que não é possível atribuir a um texto ou trecho de um texto a denominação "texto congruente" ou "texto metaforizado", pois, em diferentes graus, cada um deles possui elementos que remetem a metáforas gramaticais.

No exemplo discutido, elementos constituintes do texto sofreram modificações em suas funções iniciais, como apresentado seguir:

O texto $\Leftrightarrow$ Participante (no texto original)

$\Leftrightarrow$ Circunstância (no texto modificado 1 )

$\Leftrightarrow$ Participante (no texto modificado 2)

$\Leftrightarrow$ Participante (no texto modificado 3 )

Precede $\Leftrightarrow$ Processo (no texto original)

$\Leftrightarrow$ Qualificador (no texto modificado 1)

$\Leftrightarrow$ Circunstância (substituido por "Antes" no texto modificado 2)

* Circunstância (no texto modificado 3)/Oração não-finita de gerúndio 
Pretende dar $\Leftrightarrow$ Processo (no texto original)

$\Leftrightarrow$ Processo (no texto modificado 1 )

$\Leftrightarrow$ Participante nominalizado (no texto modificado 2)

$\Leftrightarrow$ Processo (no texto modificado 3 )

Como é possível perceber, o que pode indicar se um texto é mais metafórico ou não é sua densidade lexical.

Metáforas

gramaticais

como

recurso para

Exemplo (7)

empacota-

mento no texto

Texto original (TCC)

Para que haja uma

compreensão textual

eficaz, faz-se necessá-

rio que leitor e autor

estejam, conforme

Silva $(2000$, p.43),

"sócio-historicamente

determinados $\mathrm{e}$

ideologicamente

constituídos".

- $\mathrm{n}^{\circ}$ de palavras lexi-

cais: 14

- $\mathrm{n}^{\circ}$ de orações que de-

sempenham funções

oracionais: 2

$\mathrm{DL}=14 / 2=7$
Texto modificado 1 Para uma compre-

ensão textual eficaz,

leitor e autor devem

estar "sócio-histori-

camente determina-

dos e ideologicamente

constituídos" (SILVA,

2000, p.43).

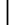

Texto modificado 2 Leitor e autor

"sócio-historicamente

determinados $\mathrm{e}$

ideologicamente cons-

tituidos" (SILVA, 2000,

p.43) podem chegar

a uma compreensão

textual eficaz.
Texto modificado 3 Segundo Silva (2000, p.43), um texto só poderá ser compreendido eficazmente

se leitor e autor esti-

verem "sócio-histori-

camente determina-

dos e ideologicamente constituidos".

acadêmico

Nesse exemplo, pode-se observar os modos como os processos foram modificados, mantendo sua característica de modalidade:

Faz-se necessário

Devem estar

Podem chegar a

Poderá ser compreendido
$\Leftrightarrow$ Processo Relacional (no texto original)

$\Leftrightarrow$ Processo Relacional (no texto modificado 1)

$\Leftrightarrow$ Processo Material (no texto modificado 2)

$\Leftrightarrow$ Processo Relacional (no texto modificado 3 )

Outro elemento modificado é "eficaz":

Eficaz $\Leftrightarrow$ Qualificador (no texto original, texto modificado 1, texto modificado 2)

* Circunstância (no texto modificado 3)

Leitor e autor assumem o papel de participantes tanto no texto original quanto nos modificados, porém, em níveis diferentes: em ora- 
ções hipotáticas no texto original e no modificado 3; em orações domi-

Maria Otilia nantes nos textos modificados 1 e 2 .

Guimarães

Ninin

\section{Exemplo (8)}

Norma Lírio

de Leão Joseph

Alda Maria

Coimbra

Maciel

\begin{tabular}{|l|l|}
\hline $\begin{array}{l}\text { Texto original (TCC) } \\
\text { Concluímos que os gêneros expostos } \\
\text { são favoráveis à leitura crítica, pelas } \\
\text { mesmas razões que os consideramos } \\
\text { adequados aos objetivos propostos, } \\
\text { apesar de pensarmos que a leitura } \\
\text { crítica não é estimulada, incentivada } \\
\text { e desenvolvida de maneira satisfató- } \\
\text { ria por esse livro didático. }\end{array}$ & $\begin{array}{l}\text { Texto modificado 1 } \\
\text { Embora adequado aos objetivos } \\
\text { propostos, os estímulos e incentivos } \\
\text { presentes nesse livro, no que tange } \\
\text { ao trabalho com gêneros, não desen- } \\
\text { voritica. }\end{array}$ \\
\hline $\begin{array}{l}\text { - } \mathrm{n}^{\circ} \text { de palavfatoriamente a leitura } \\
-\mathrm{n}^{\circ} \text { de orações que desempenham } \\
\text { funções oracionais: } 5\end{array}$ & $\begin{array}{l}\text { - } \mathrm{n}^{\circ} \text { de palavras lexicais: } 15 \\
-\mathrm{n}^{\circ} \text { de orações que desempenham } \\
\text { funções oracionais: } 1\end{array}$ \\
\hline $\mathrm{DL}=24 / 5=4,8$ & $\mathrm{DL}=15 / 1=15$ \\
\hline
\end{tabular}

Observa-se, nesse exemplo (8), não só o texto modificado 1 com maior densidade lexical do que o texto original, mas o modo como as orações hipotáticas foram transformadas para o encapsulamento do texto. Vale notar que a eliminação de alguns processos ("concluímos", “considerarmos", "pensarmos") leva à eliminação do agente, impessoalizando o evento, o que ocorre também no exemplo (9), a seguir:

\section{Exemplo (9)}

\begin{tabular}{|l|l|}
\hline $\begin{array}{l}\text { Texto original (TCC) } \\
\text { Salientamos o fato de que tanto os } \\
\text { PCNs quanto o PNLD 2008 fazem men- } \\
\text { ção a esse conceito e apóiam o trabalho } \\
\text { com os gêneros, sendo que os PCNs } \\
\text { são totalmente pautados na teoria dos } \\
\text { Gêneros do Discurso bakhtiniana. }\end{array}$ & $\begin{array}{l}\text { Texto modificado 1 } \\
\text { Em apoio ao trabalho com gêneros, } \\
\text { tanto PCNs, totalmente pautados na } \\
\text { teoria bakhtiniana dos Gêneros do } \\
\text { Discurso, quanto PNLD 2008, men- } \\
\text { cionam tal conceito. }\end{array}$ \\
\hline $\begin{array}{l}\text { - } \mathrm{n}^{\circ} \text { de palavras lexicais: } 19 \\
-\mathrm{n}^{\circ} \text { de orações que desempenham } \\
\text { funções oracionais: } 5\end{array}$ & $\begin{array}{l}-\mathrm{n}^{\text {}} \text { de palavras lexicais: } 13 \\
-\mathrm{n}^{\circ} \text { de orações que desempenham } \\
\text { funções oracionais: } 1\end{array}$ \\
\hline DL $=19 / 5=3,8$ & $\mathrm{DL}=13 / 1=13$ \\
\hline
\end{tabular}

Ao suprimir o agente (com a supressão dos processos "salientamos", “apoiam"), suprime-se também parte da realidade. 0 texto científico prima pela presença desse texto lexicalmente denso, ainda que fique ofuscado o agente. 


\section{Exemplo (10)}

\begin{tabular}{|l|l|}
\hline $\begin{array}{l}\text { Texto original (MS) } \\
\text { A visão sobre emoção que Darwin ofe- } \\
\text { rece é bastante positiva, já que todas ex- } \\
\text { pressões e todos movimentos corporais } \\
\text { provenientes da emoção são necessários } \\
\text { para a preservação da espécie, e, portan- } \\
\text { to, vão sempre ao encontro da vida. }\end{array}$ & $\begin{array}{l}\text { Texto modificado 1 } \\
\text { A favorável visão darwiniana sobre } \\
\text { emoção corrobora a importância } \\
\text { das expressões e movimentos corpo- } \\
\text { rais a ela relacionadas na preserva- } \\
\text { ção da espécie, ao encontro da vida. }\end{array}$ \\
\hline $\begin{array}{l}\text { - } \mathrm{n}^{\circ} \text { de palavras lexicais: } 20 \\
\text { - } \mathrm{n}^{\circ} \text { de orações que desempenham } \\
\text { funções oracionais: } 4\end{array}$ & $\begin{array}{l}\text { - } \mathrm{n}^{\circ} \text { de palavras lexicais: } 14 \\
-\mathrm{n}^{\circ} \text { de orações que desempenham } \\
\text { funções oracionais: } 1\end{array}$ \\
\hline $\mathrm{DL}=20 / 4=5$ & $\mathrm{DL}=14 / 1=14$ \\
\hline
\end{tabular}

Em (10), há uma redução nos processos - "oferece" (processo material transformativo), "são" (processo relacional) e "vão" (processo material transformativo) são encapsulados por "corrobora" (processo material transformativo). Nesse movimento entre os textos original e modificado, modificam-se as funções também de outros elementos: a "visão" - de participante Portador (do processo relacional "é") para participante Ator (do processo material "corrobora"); "Darwin" - de participante Ator (do processo material "oferece") para "darwiniana", Qualificador do participante "visão"; "bastante" - Quantificador do epíteto "positiva", ambos qualificando o participante Portador "visão" (do processo Relacional “é"), para "favorável”, Qualificador também do participante "visão" (do processo material “corrobora").

\section{Exemplo (11)}

\begin{tabular}{|l|l|}
\hline $\begin{array}{l}\text { Texto original (MS) } \\
\text { Utilizando-se de metodologia } \\
\text { introspectiva, a autora verifica as } \\
\text { estratégias utilizadas pelos leitores } \\
\text { na decodificação de elementos de } \\
\begin{array}{l}\text { foregrounding e nota que, ao passar } \\
\text { pelo processo de refamiliarização, os } \\
\text { leitores mudam suas perspectivas } \\
\text { sobre o mundo à sua volta. }\end{array}\end{array}$ & $\begin{array}{l}\text { Texto modificado 1 } \\
\text { Por meio de metodologia introspecti- } \\
\text { va, a autora, observando estratégias } \\
\text { utilizadas por leitores na decodifica- } \\
\text { ção de elementos de foregrounding, } \\
\text { nota mudança em suas perspectivas } \\
\text { sobre o mundo à sua volta, a partir } \\
\text { do processo de refamiliarização. }\end{array}$ \\
\hline $\begin{array}{l}\text { - } \mathrm{n}^{\circ} \text { de palavras lexicais: } 20 \\
\text { - } \mathrm{n}^{\circ} \text { de orações que desempenham } \\
\text { funções oracionais: } 5\end{array}$ & $\begin{array}{l}\text { - } \mathrm{n}^{\circ} \text { de palavras lexicais: } 17 \\
\text { - } \mathrm{n}^{\circ} \text { de orações que desempenham } \\
\text { funções oracionais: } 1\end{array}$ \\
\hline $\mathrm{DL}=20 / 5=4$ & $\mathrm{DL}=17 / 1=17$ \\
\hline
\end{tabular}

Metáforas

gramaticais

como

recurso para

empacota-

mento no texto

acadêmico 
Nesse exemplo (11), o encapsulamento do texto se dá, ini-

Maria Otilia

Guimarães

Ninin

Norma Lírio

de Leão Joseph

Alda Maria

Coimbra

Maciel cialmente, pela supressão dos processos "utilizando", "verifica", "passar" e "mudam", retextualizados em um único processo: "nota", mental cognitivo. "Estratégias utilizadas pelos leitores na decodificação de elementos de foregrounding", participante Ator do processo material transformativo "verifica", é modificado para uma oração hypotática que funciona como circunstância de Modo. "Leitores", que no texto original assume o papel de participante Ator (do processo material “mudam"), passa, no texto modificado, a participante Beneficiário (do processo material “utilizadas").

\section{Exemplo (12)}

\begin{tabular}{|c|c|}
\hline $\begin{array}{l}\text { Texto original (DO) } \\
\text { O uso da língua é influenciado pelos } \\
\text { fatores sociais que atuam na repre- } \\
\text { sentação das situações discursivas. } \\
\text { Dentre esses fatores, pode-se dizer } \\
\text { que a estratificação da sociedade em } \\
\text { classes exerce grande influência na } \\
\text { valorização das normas e variedades } \\
\text { linguísticas que apresentam pres- } \\
\text { tígios sócio-históricos e culturais } \\
\text { diferentes. }\end{array}$ & $\begin{array}{l}\text { Texto modificado } 1 \\
\text { Os fatores sociais, principalmente } \\
\text { a estratificação da sociedade em } \\
\text { classes nas situações discursivas, } \\
\text { influenciam o uso da língua através } \\
\text { das normas e variedades linguísti- } \\
\text { cas sócio-histórica e culturalmente } \\
\text { diferentes. }\end{array}$ \\
\hline $\begin{array}{l}\text { - } \mathrm{n}^{\circ} \text { de palavras lexicais: } 27 \\
\text { - } \mathrm{n}^{\circ} \text { de orações que desempenham } \\
\text { funções oracionais: } 5\end{array}$ & $\begin{array}{l}\text { - } \mathrm{n}^{\circ} \text { de palavras lexicais: } 18 \\
-\mathrm{n}^{\circ} \text { de orações que desempenham } \\
\text { funções oracionais: } 1\end{array}$ \\
\hline $\mathrm{DL}=27 / 5=5,4$ & $\mathrm{DL}=18 / 1=18$ \\
\hline
\end{tabular}

O texto original, nesse exemplo (12), com 5 orações (processos), passa, no texto metaforizado, a uma única oração (processo). "Os fatores sociais", em posição temática e como participante Ator no texto modificado, evidencia o encadeamento semântico-discursivo desse texto em direção à língua como fator social. Destaca-se, desta forma, uma sequência textual metaforizada gramaticalmente, que possibilita o aprendizado de uma escrita mais encapsulada. 


\section{Exemplo (13)}

\begin{tabular}{|c|c|}
\hline $\begin{array}{l}\text { Texto original (DO) } \\
\text { A análise que fizemos dos textos escritos } \\
\text { por esses participantes revelou inade- } \\
\text { quações das escolhas linguísticas quanto } \\
\text { à situação de produção/recepção textual } \\
\text { (principalmente quanto à regência e à } \\
\text { pontuação). Esse dado levou-nos a consi- } \\
\text { derar que o ensino pautado nos estudos } \\
\text { da metalinguagem não é profícuo no } \\
\text { aprendizado da norma padrão. }\end{array}$ & $\begin{array}{l}\text { Texto modificado } 1 \\
\text { Através da análise, a revelação de } \\
\text { inadequações das escolhas linguísticas } \\
\text { dos textos dos participantes quanto à } \\
\text { produção/recepção textual indica a inefi- } \\
\text { cácia no ensino, pautado nos estudos da } \\
\text { metalinguagem. }\end{array}$ \\
\hline $\begin{array}{l}\text { - } \mathrm{n}^{\circ} \text { de palavras lexicais: } 28 \\
\text { - } \mathrm{n}^{\circ} \text { de orações que desempenham fun- } \\
\text { ções oracionais: } 5\end{array}$ & $\begin{array}{l}\text { - } \mathrm{n}^{\circ} \text { de palavras lexicais: } 17 \\
-\mathrm{n}^{\circ} \text { de orações que desempenham fun- } \\
\text { ções oracionais: } 1\end{array}$ \\
\hline $\mathrm{DL}=28 / 5=5,6$ & $\mathrm{DL}=17 / 1=17$ \\
\hline
\end{tabular}

No texto modificado desse exemplo (13), o encapsulamento propicia, através da nominalização, a mudança nas funções morfológicas - revelou (verbo/processo) modificado para "revelação" (substantivo/coisa); não profícuo (adjetivo/ atributo) modificado para "ineficácia" (substantivo/coisa) distinguindo, portanto, o uso do conceito/ideia que conduz ao aprendizado das características da escrita acadêmica.

\section{Metáforas \\ gramaticais \\ como \\ recurso para \\ empacota- \\ mento no texto \\ acadêmico}

\section{Exemplo (14)}

\begin{abstract}
Texto original (AC)
Foi com o propósito de conciliar sua abordagem dos enunciados negativos com uma visão polifônica da linguagem que Ducrot procedeu a uma revisão teórica do fenômeno, passando a subdividir a antiga negação polêmica em dois tipos distintos (a que denominou negação metalinguística e a negação polêmica), redefinindo o conceito de negação descritiva. Em o dizer e o dito, o quadro teórico passa a ser o seguinte: a negação metalinguística coloca em cena um locutor responsável pelo enunciado positivo implícito, agindo sobre seus pressupostos; a negação polêmica se define como sendo a que coloca em cena não um locutor, mas um enunciador responsável por uma afirmativa virtual implícita; a negação descritiva passa a ser caracterizada como um derivado delocutivo da negação polêmica.
\end{abstract}

- $\mathrm{n}^{\circ}$ de palavras lexicais: 67

- $\mathrm{n}^{\circ}$ de orações que desempenham funções oracionais: 11

\section{Texto modificado 1}

Conciliando a abordagem dos enunciados negativos à visão polifônica da linguagem, Ducrot, a partir da revisão teórica do fenômeno, subdivide a antiga negação polêmica em dois tipos distintos (a metalinguística e a polêmica), redefinindo negação descritiva. Em o dizer e o dito, tem-se como quadro teórico a negação: (a) metalinguística, com um locutor responsável pelo enunciado positivo implícito, que age sobre seus pressupostos; (b) polêmica, não com um locutor, mas com um enunciador responsável por uma afirmativa virtual implícita; (c) descritiva, caracterizada como um derivado delocutivo da negação polêmica.

\begin{tabular}{l|l}
$\mathrm{DL}=67 / 11=6$ & $\mathrm{DL}=50 / 5=10$
\end{tabular}


Tem-se, nesse exemplo (14), uma variação da densidade lexi-

Maria Otilia

Guimarães

Ninin

Norma Lírio

de Leão Joseph

Alda Maria

Coimbra

Maciel

226

cal, resultante da supressão de alguns verbos: "passando a subdividir" modificado para "subdivide"; "passa a ser" modificado para "tem-se"; "define como sendo a que coloca" modificado para um elemento vazio; "passa a ser caracterizada" modificado para um elemento vazio. 0 que no texto original era uma oração material ("Ducrot procedeu a uma revisão teórica do fenômeno") passa a ser uma circunstância ("a partir da revisão da teoria do fenômeno"), que funciona como circunstância de Modo. Vale notar também que no texto original tem-se "a negação metalinguística", "a negação polêmica" e "a negação descritiva", no segundo período, como participantes, respectivamente, dos processos “coloca", "define" e "passa a ser". Já no texto modificado, essas três expressões assumem o papel de participantes de um único processo, o Existencial "tem-se". "Revisão teórica do fenômeno" passa de participante do processo material "procedeu" a uma circunstância - "a partir da revisão teórica do fenômeno". Assim, o que se propõe no texto modificado 1 torna mais complexa a relação entre os níveis da léxico-gramática e da semântica do discurso.

\section{Exemplo (15)}

\begin{tabular}{|c|c|}
\hline $\begin{array}{l}\text { Texto original (AC) } \\
\text { A referida leitura descritiva do enun- } \\
\text { ciado negativo é resultante de uma } \\
\text { derivação descritiva: há contextos } \\
\text { que, promovendo o apagamento } \\
\text { do enunciado positivo subjacente, } \\
\text { isto é, bloqueando a atualização do } \\
\text { ponto de vista que desencadeia uma } \\
\text { leitura polêmica da negação, favore- } \\
\text { cem tal derivação. }\end{array}$ & $\begin{array}{l}\text { Texto modificado } 1 \\
\text { A referida leitura descritiva do enun- } \\
\text { ciado negativo resulta de uma deri- } \\
\text { vação descritiva: alguns contextos, } \\
\text { por meio de bloqueio da atualização } \\
\text { do ponto de vista desencadeador } \\
\text { de uma leitura polêmica da nega- } \\
\text { ção, favorecem tal derivação pelo } \\
\text { apagamento do enunciado positivo } \\
\text { subjacente. }\end{array}$ \\
\hline $\begin{array}{l}\text { - } \mathrm{n}^{\circ} \text { de palavras lexicais: } 26 \\
-\mathrm{n}^{\circ} \text { de orações que desempenham } \\
\text { funções oracionais: } 4\end{array}$ & $\begin{array}{l}\text { - } n^{\circ} \text { de palavras lexicais: } 23 \\
-n^{\circ} \text { de orações que desempenham } \\
\text { funções oracionais: } 2\end{array}$ \\
\hline $\mathrm{DL}=26 / 4=6,5$ & $\mathrm{DL}=23 / 2=11,5$ \\
\hline
\end{tabular}

O que se tem nesse exemplo (15) é a mudança na configuração dos processos e participantes, para se produzir um texto mais metaforizado. O processo existencial "há", cujo Existente é "contextos", desaparece e dá lugar, no texto modificado, a "alguns", Quantificador de "contextos", agora participante do processo material "favorecem". 
"Promovendo", "bloqueando", processos que no texto original compõem orações hipotáticas, e "desencadeia", que compõe uma oração encaixada, são modificados: o primeiro, desaparecendo; o segundo, nominalizado - "bloqueio"; e o terceiro, agora como Qualificador. Tanto no texto original quanto no modificado tem-se um alto índice de nominalizações, recurso altamente persuasivo utilizado com frequência na escrita acadêmica mais prestigiada.

\section{À GUISA DE CONCLUSÃo}

Como destacado no início do capítulo, objetivou-se explorar e discutir a metáfora gramatical em textos acadêmicos, para pensá-la como recurso a ser utilizado por alunos-autores na academia. Foram destacados exemplos de textos com diferentes níveis de metaforização e modos de

Metáforas gramaticais como recurso para empacotamento no texto acadêmico realizá-la, sempre a partir da modificação das funções dos elementos integrantes dos textos.

Propostas de atividades de ensino da escrita acadêmica na direção das discussões apresentadas neste capítulo visam propiciar ao aluno contextos para que investigue não somente seu próprio texto, a fim de aprimorá-lo, mas outros textos acadêmicos produzidos tanto por autores mais experientes quanto iniciantes, que tragam a diversidade nos modos de escrita e permitam a análise dos modos de organizar os enunciados.

Orientações para uma atividade pedagógica, discutidas a seguir, não têm a pretensão de servir como modelo ao ensino da escrita acadêmica, mas sim como elemento de reflexão aos professores e orientadores de trabalhos. $O$ que se espera é que, ao desenvolver atividades a partir de recortes de textos reais, os autores-alunos reflitam sobre a funcionalidade de cada elemento da língua e sobre os modos mais e menos congruentes de organizá-los - as metáforas gramaticais - para a produção de significados.

A atividade sugerida pode iniciar-se pela exposição do aluno-autor ao gênero científico, por meio do manuseio de diferentes trabalhos (TCCs, dissertações, teses, artigos científicos). Objetiva-se nessa fase, além da observação do gênero, provocar uma discussão sobre o papel social da escrita acadêmica. Na sequência, a atividade prevê o uso das linhas de concordância oferecidas pelo programa WordSmith Tools (SCOTT, 2009), sugerindo a investigação na direção de: 
Maria Otilia

Guimarães

Ninin

Norma Lírio

de Leão Joseph

Alda Maria

Coimbra

Maciel

228

a) Observação: exercícios que possibilitem ao aluno-autor destacar elementos como: verbos flexionados (para encontrar orações e complexos oracionais, para transformá-los em nominalizações); orações relativas não definidoras (para transformá-las em orações encaixadas); qualificadores (para transformá-los em nomes); nomes (para transformá-los em dêiticos possessivos); orações não finitas (para transformá-las em qualificadores); nominalizações (para compreender sua origem e as transformações pelas quais passaram);

b) Tratamento: exercícios que possibilitem ao aluno-autor realizar diferentes modificações nos segmentos textuais apresentados (linhas de concordância), comparando-os a partir de sua densidade lexical;

c) Elaboração: exercícios de reescrita de seu próprio texto a partir de identificações de elementos cujas funções podem ser modificadas para produzir um texto mais encapsulado.

O que se pretendeu mostrar neste capítulo foi a importância da compreensão dos mecanismos de encapsulamento da escrita, dado o fato de que diferentes modos de apresentar um texto reflete diferentes finalidades em função dos contextos aos quais servem (SCHLEPPEGRELL, 2004). A análise linguística dessas características do texto mais encapsulado pode favorecer o desenvolvimento da competência escritora de alunos-autores nos diferentes segmentos escolares e, em específico, na academia, foco aqui discutido. Trabalhou-se, neste capítulo, com registros textuais de autores pertencentes a um contexto específico de uso da língua, que buscam seu aprimoramento - o estudante de graduação, com seu TCC; o autor-mestre e o autor-doutor, em uma etapa mais avançada dos conhecimentos linguísticos; o autor proficiente por excelência, produtor dos artigos científicos. Os exemplos selecionados para discussão, representativos, ainda que parcialmente, de textos dos diferentes níveis de produção acadêmica, revelaram os desafios enfrentados por autores na produção da escrita acadêmica, mostrando a importância do trabalho de orientação e ensino com foco na análise linguística dessa escrita. 


\section{Referências}

ARISTÓTELES. Poética: os pensadores. São Paulo: Abril, 1999.

EGGINS, S.; MARTIN, J.R. Genres and registers of discourse. In: Van Metáforas DIJK, T.A. (ed.). Discourse as Structure and Process. Discourse gramaticais Studies: A Multidisciplinary Introduction, Volume 1. London: Sage Publications, 1997. p. 230-256.

como recurso para empacota-

FAIRCLOUGH, N. Analysing discourse: textual analysis for social research. New York: Routledge, 2003. mento no texto acadêmico

FARAHANI, A.A.; HADIDI, Y. Semogenesis under Scrutiny: Grammatical Metaphor in Science and Modern Prose Fiction. IJAL, Vol. 11, $\mathrm{n}^{\circ}$ 2, September, 51-85, 2008.

GOUVEIA, C. A. M. Aspectos do uso de orações encaixadas num corpus de desenvolvimento da escrita no ensino básico. GRATO Conferência Internacional sobre Gramática e Texto. Faculdade de Ciências Sociais e Humanas da Universidade Nova de Lisboa, 2009.

HALLIDAY, M.A.K. An Introduction to Functional Grammar. London: Hodder Arnold, 1985.

An Introduction to Functional Grammar. $2^{\text {nd }}$ ed. London: Hodder Arnold, 1994.

On Grammar. London: Continuum, 2002.

An Introduction to Functional Grammar. $3^{\text {rd }}$ ed. London: Hodder Arnold, 2004.

HEYVAERT, L. Nominalization as grammatical metaphor. On the need for a radically systemic and metafunctional approach. In: SIMON-VANDENBERGEN, A.-M.; TAVERNIERS, M. Grammatical Metaphor: Views from systemic functional linguistics. Amsterdam: Benjamins, 2003. p. 65-99. 

Maria Otilia
Guimarães
Ninin
Norma Lírio
de Leão Joseph
Alda Maria
Coimbra
Maciel
RAVELLI, L. Grammatical metaphor. An initial analysis. In: STEINER, E.H.; VeltMAn, R. (eds.) Pragmatics, Discourse and Text. Some systemically-oriented approaches. London: Pinter, 1988. p. 133-147.
SANTOS, A.L.; CARMO, C.M. Sobre a legitimação da autoridade cien- tífica: uma compreensão dos artifícios avaliativo-discursivos que asseguram um poder. Krypton, Anno I, n. 1, 103-114, 2013. Roma TrE-Press, Roma, aprile 2013. Disponível em: <http://host.uniroma3.it/ progetti/romatrepress/Krypton/Krypton_I_13.pdf Acesso em: 12.jul.2013.
SARDINHA, T.B. Metáfora. São Paulo: Parábola Editorial, (Lingua[gem]; 24), 2007.

230
SCHLEPPEGRELL, M.J. The Language of Schooling. A Functional Linguistics Perspective. Mahwah, NJ: Lawrence Erlbaum Associates, 2004.

SCOTT, M. Programa Word Smith Tools. Oxford University Press, 2009.

TAVERNIERS, M. Grammatical metaphor in SFL: A historiography of the introduction and initial study of the term. In: SIMON-VANDENBERGEN, A.-M.; TAVERNIERS, M.; RAVELLI, L. (eds.) Grammatical Metaphor: Views from systemic functional linguistics. Amsterdam: Benjamins, 2003.

WEBSTER, J.J. Introduction. In: HALLIDAY, M.A.K.; . (eds.) Continuum Companion to Systemic Functional Linguistics. London; New York: Continuum International Publishing Group, 2009, p. 01-11. 